\title{
Photosynthetic responses of a humid grassland ecosystem to future climate perturbations
}

\author{
Cheng-I Hsieh ${ }^{\mathrm{a}, *}$, Ger Kiely ${ }^{\mathrm{b}}$, Adrian Birkby ${ }^{\mathrm{b}}$, Gabriel Katul ${ }^{\mathrm{c}, \mathrm{d}}$ \\ a Department of Bioenvironmental Systems Engineering, National Taiwan University, 1 Roosevelt Road, Sec. 4, Taipei 10673, Taiwan \\ ${ }^{\mathrm{b}}$ Department of Civil and Environmental Engineering, University College Cork, Cork, Ireland \\ ${ }^{c}$ Nicholas School of the Environment and Earth Sciences, Duke University, Durham, NC 27708-0328, USA \\ ${ }^{\mathrm{d}}$ Department of Civil and Environmental Engineering, Duke University, Durham, NC 27708, USA
}

Received 1 June 2004; received in revised form 20 January 2005; accepted 6 February 2005

Available online 10 May 2005

\begin{abstract}
Increases in atmospheric $\mathrm{CO}_{2}$ concentration not only affects climate variables such as precipitation and air temperature, but also affects intrinsic ecosystem physiological properties such as bulk stomatal conductance and intercellular $\mathrm{CO}_{2}$ concentration. De-convolving these two effects remains uncertain in biosphere-atmosphere water and carbon cycling. Using a simplified analytical net ecosystem $\mathrm{CO}_{2}$ exchange (NEE) model, tested with recently collected flux measurements in a humid grassland ecosystem in Ireland, we assess how much projected climate shifts affect net canopy photosynthesis $(A)$ without physiological adjustments and contrast those findings with published field data on physiological adjustments for several grassland ecosystems. Our analysis suggests that the intrinsic grassland ecosystem physiological adjustment of $A$ is about 45 times more important than the resulting climatic forcing shifts from the IS92a scenario (and a doubling of atmospheric $\mathrm{CO}_{2}$ concentration). Also, our analysis shows that increase in precipitation results in concomitant decrease in the two climate variables - net radiation and vapor pressure deficit, and these decreases have opposite (and almost canceling) effects on $A$. Implications to afforestation policy and future experimental efforts to quantify the carbon sink from humid grassland ecosystems are also discussed.
\end{abstract}

(C) 2005 Elsevier Ltd. All rights reserved.

Keywords: Canopy photosynthesis; Evapotranspiration; Humid grasslands; Net ecosystem exchange

\section{Introduction}

Grasslands cover about $40 \%$ of the ice-free global terrestrial surface, but their contribution to water and carbon fluxes and sensitivity to climatic perturbations remains uncertain [17]. Increases in atmospheric $\mathrm{CO}_{2}$ concentration $\left(C_{\mathrm{a}}\right)$ have two impacts on grassland ecosystems - they modify climate-forcing variables such as precipitation $(P)$ and air temperature $\left(T_{\mathrm{a}}\right)$, and they modify intrinsic ecosystem physiological properties such as intercellular $\mathrm{CO}_{2}$ concentration $\left(C_{\mathrm{i}}\right)$ and bulk stoma-

\footnotetext{
* Corresponding author. Tel.: +886 2 33665294; fax: +886 2 23635854.

E-mail address: hsieh@ntu.edu.tw (C.-I. Hsieh).
}

tal conductance. Using a general circulation model (GCM) coupled with a vegetation (biosphere) model, both Sellers et al. [19] and Betts et al. [2] found that increases in $C_{\mathrm{a}}$ could result in a reduced stomatal conductance and transpiration and an increased air temperature. The relative importance of shifts in climate forcing and ecophysiological adjustments on net canopy photosynthesis $(A)$, both arising from increasing $C_{\mathrm{a}}$, continues to be an active research area for grassland ecosystems (e.g., $[10,8,20]$ ). Many studies conducted thus far focus on one of these two aspects (i.e., the impacts of climate forcing shifts or ecophysiological adjustments on net canopy photosynthesis). For example, model simulation experiments on photosynthesis typically adjust for meteorological shifts yet retain 
"static" ecophysiological properties (e.g., $[15,16])$, while most ecological experiments (e.g., chamber based or free air $\mathrm{CO}_{2}$ enrichment experiments) investigate the effects of elevated $C_{\mathrm{a}}$ on $A$ while retaining similar climatic and hydrologic forcing for ambient and enriched pairs (e.g., $[11,8])$. De-convolving the relative importance of these two effects on $A$ remains an unresolved yet important problem for advancing our understanding on the potential sink for $\mathrm{CO}_{2}$ in grassland ecosystems.

Using a combination of published data, recently collected flux measurements in a humid grassland ecosystem at Cork, Ireland, and a simplified analytical model developed in this study, we assess how much projected climate shifts affect net photosynthesis in humid grasslands without physiological adjustments and contrast those findings with physiological adjustments already published for several grassland ecosystems with elevated atmospheric $\mathrm{CO}_{2}$ being the only altered variable. The humid grassland ecosystems are a logical starting point for our investigation as they are primarily "energy" limited, and plant and soil hydraulics often exert minor control on $A$. That is, the canopy conductance can be described by two key climatic variables, available energy and vapor pressure deficit $(D)$.

Our climate projections are based on the Hadley Center GCM output for Ireland in which $C_{\mathrm{a}}$ doubles over the course of the 21st century and leads to changes in the seasonal $P$ fluctuations. The main novelty in our analysis is an explicit treatment of the interplay between changes in $P$ (which is the key variable forecasted by GCM's), net radiation $\left(R_{\mathrm{n}}\right)$, and $D$. For example, increases in $P$ may well be accompanied by decreases in $R_{\mathrm{n}}$ due to reduction in cloud cover, which decreases both transpiration and carbon uptake. However, increases in $P$ are also accompanied by decreases in $D$, which increases canopy conductance and carbon uptake.

We compare the effects of climate shifts predicted by the GCM on modeled $A$ with results from two experiments that explicitly considered how elevated $C_{\mathrm{a}}$ alters the intrinsic physiological properties of grasslands (retaining all other climatic variables unaltered). Our objective is to assess how much the effects of elevated $C_{\mathrm{a}}$ are realized in climate forcing shifts or intrinsic eco-physiological adjustments.

\section{Theory}

To achieve the study objective, we first propose a simplified water-carbon model and then conduct an analysis on how perturbations in $C_{\mathrm{a}}$, climatic (e.g., $R_{\mathrm{n}}$ and $D$ ), and physiological factors (e.g., $C_{\mathrm{i}}$ ) manifest themselves in $A$.

\subsection{Simplified water-carbon model}

For humid regions, the latent heat flux, LE $\left(\mathrm{W} \mathrm{m}^{-2}\right)$, can be calculated by the Penman-Monteith equation
$\mathrm{LE}=\frac{\Delta Q_{\mathrm{n}}+\rho c_{p} D / r_{\mathrm{av}}}{\Delta+\gamma\left(1+r_{\mathrm{st}} / r_{\mathrm{av}}\right)}$,

where $\Delta\left(\mathrm{kPa} \mathrm{K}^{-1}\right)$ is the slope of the saturation vapor pressure-temperature curve calculated at the air temperature $T_{\mathrm{a}}, \gamma\left(=\frac{\rho c_{p}}{0.622 L_{\mathrm{v}}}\right)$ is the psychrometric constant, $\rho\left(\approx 1.2 \mathrm{~kg} \mathrm{~m}^{-3}\right)$ is the mean air density, $c_{p}$ $\left(=1005 \mathrm{~J} \mathrm{~kg}^{-1} \mathrm{~K}^{-1}\right)$ is the specific heat for air, $L_{\mathrm{v}}$ $\left(=2.46 \times 10^{6} \mathrm{~J} \mathrm{~kg}^{-1}\right)$ is the latent heat of vaporization, $Q_{\mathrm{n}}=R_{\mathrm{n}}-G_{\mathrm{s}}, R_{\mathrm{n}}$ is, as before, the net radiation, $G_{\mathrm{s}}$ is the soil heat flux $\left(\mathrm{W} \mathrm{m}^{-2}\right), D$ is, as before, the vapor pressure deficit $(\mathrm{kPa}), r_{\mathrm{av}}$ is the aerodynamic resistance of water vapor $\left(\mathrm{s} \mathrm{m}^{-1}\right)$, and $r_{\mathrm{st}}$ is the minimum bulk stomatal resistance to water vapor $\left(\approx 100 \mathrm{~s} \mathrm{~m}^{-1}\right.$ for the current grass site). In (1), $r_{\mathrm{av}}$ can be estimated by

$r_{\mathrm{av}}=\frac{k u_{*}}{\ln \left(z / z_{0}\right)-\psi_{\mathrm{m}}(z / L)}$,

where $k(=0.4)$ is the von Karman constant, $u *$ is the friction velocity $\left(\mathrm{m} \mathrm{s}^{-1}\right), z$ is the measurement height, $z_{0}$ is the surface roughness, and $\psi_{\mathrm{m}}(z / L)$ is the stability correction function for momentum and $L$ is the Obukhov length (see [3]). Eqs. (1) and (2) can be solved iteratively to incorporate the influence of thermal stability on $r_{\mathrm{av}}$.

The canopy conductance (boundary layer conductance plus stomatal conductance) for $\mathrm{CO}_{2}$ can be calculated by [4]

$g_{\mathrm{CO}_{2}}=\frac{P_{\mathrm{a}} \mathrm{LE}}{1.6 D L_{\mathrm{v}} M_{\mathrm{w}}}$,

where $g_{\mathrm{CO}_{2}}$ is the canopy conductance $\left(\mathrm{mol} \mathrm{m}^{-2} \mathrm{~s}^{-1}\right)$, $M_{\mathrm{w}}\left(=0.018 \mathrm{~kg} \mathrm{~mol}^{-1}\right)$ is the molecular weight of water, $P_{\mathrm{a}}$ is the atmospheric pressure $(\mathrm{kPa})$, and the factor 1.6 is due to the difference in molecular diffusivity between water vapor and $\mathrm{CO}_{2}$. The net canopy photosynthesis, $A$, can be expressed as

$A=g_{\mathrm{CO}_{2}} \times C_{\mathrm{a}} \times\left(1-\frac{C_{\mathrm{i}}}{C_{\mathrm{a}}}\right)$,

where $C_{\mathrm{i}}$ is, as before, the "canopy-averaged" intercellular $\mathrm{CO}_{2}$ concentration in ppm, $C_{\mathrm{a}}$ in ppm, and $A$ in $\mu \mathrm{mol} \mathrm{m} \mathrm{m}^{-2} \mathrm{~s}^{-1}$. By replacing (1) and (3) in (4), we have

$A=\left(\frac{P_{\mathrm{a}}}{1.6 L_{\mathrm{v}} M_{\mathrm{w}}}\right)\left(\frac{\Delta Q_{\mathrm{n}}+\rho c_{p} D / r_{\mathrm{av}}}{\Delta+\gamma\left(1+r_{\mathrm{st}} / r_{\mathrm{av}}\right)}\right)\left(\frac{C_{\mathrm{a}}}{D}\right)\left(1-\frac{C_{\mathrm{i}}}{C_{\mathrm{a}}}\right)$.

Eq. (5) was derived by assuming that the bulk stomatal conductance is mainly driven by available energy and vapor pressure deficit with no soil moisture controls, as is expected in humid grasslands (and the reason why they serve as a logical starting point for such an analysis).

\subsection{Internal physiological shifts versus climatic shifts}

Eq. (5) shows how photosynthesis varies with "climatic" factors such as $Q_{\mathrm{n}}, C_{\mathrm{a}}, D$ and "physiological" 
parameters such as $C_{\mathrm{i}} / C_{\mathrm{a}}$ and $r_{\mathrm{st}}$. Hence, it is possible to analytically track how shifts in climatic and physiological factors alter photosynthesis using multivariate calculus. Noting that $A=f\left(Q_{\mathrm{n}}, C_{\mathrm{a}}, D, C_{\mathrm{i}} / C_{\mathrm{a}}, r_{\mathrm{st}}\right)$, the total derivative can be expressed as

$$
\begin{aligned}
\mathrm{d} A= & \left(\frac{\partial A}{\partial Q_{\mathrm{n}}}\right) \mathrm{d} Q_{\mathrm{n}}+\left(\frac{\partial A}{\partial C_{\mathrm{a}}}\right) \mathrm{d} C_{\mathrm{a}}+\left(\frac{\partial A}{\partial D}\right) \mathrm{d} D \\
& +\left(\frac{\partial A}{\partial\left(C_{\mathrm{i}} / C_{\mathrm{a}}\right)}\right) \mathrm{d}\left(C_{\mathrm{i}} / C_{\mathrm{a}}\right)+\left(\frac{\partial A}{\partial r_{\mathrm{st}}}\right) \mathrm{d} r_{\mathrm{st}} .
\end{aligned}
$$

Upon evaluating all the partial derivative terms using the formulation in (5) and replacing them in (6a), dividing by Eq. (5), and re-arranging, the projected shift in photosynthesis $(\mathrm{d} A)$ can be related analytically to shifts in $Q_{\mathrm{n}}, C_{\mathrm{a}}, D, C_{\mathrm{i}} / C_{\mathrm{a}}$, and $r_{\mathrm{st}}$ by

$$
\begin{aligned}
\frac{\mathrm{d} A}{A}= & \frac{\mathrm{d} C_{\mathrm{a}}}{C_{\mathrm{a}}}-\left(\frac{\Delta Q_{\mathrm{n}} \mathrm{d} D}{\left(\Delta Q_{\mathrm{n}}+\rho c_{p} D / r_{\mathrm{av}}\right) D}-\frac{\Delta \mathrm{d} Q_{\mathrm{n}}}{\Delta Q_{\mathrm{n}}+\rho c_{p} D / r_{\mathrm{av}}}\right) \\
& -\left(\frac{\left(\gamma / r_{\mathrm{av}}\right) \mathrm{d} r_{\mathrm{st}}}{\Delta+\gamma\left(1+r_{\mathrm{st}} / r_{\mathrm{av}}\right)}+\frac{\mathrm{d}\left(C_{\mathrm{i}} / C_{\mathrm{a}}\right)}{1-\left(C_{\mathrm{i}} / C_{\mathrm{a}}\right)}\right) \\
\mathrm{I}= & \mathrm{II}-(\mathrm{III}-\mathrm{IV})-(\mathrm{V}+\mathrm{VI})
\end{aligned}
$$

In (6b), the second term (II) is the relative change in photosynthesis due to increases in $C_{\mathrm{a}}$, the third and forth terms (III and IV) represent the shifts by climatic variables (i.e., changes in $D$ and $Q_{\mathrm{n}}$ ), and the fifth and sixth terms (V and VI) can be interpreted as the physiological shifts. If the ratio $C_{\mathrm{i}} / C_{\mathrm{a}}$ is approximately constant for current and elevated $C_{\mathrm{a}}[7,14,12]$, then the physiological shifts are mainly from changes in the bulk stomatal resistance. In (6b), if $Q_{\mathrm{n}}$ is not available (or measured), it is reasonable to assume that $\mathrm{d} Q_{\mathrm{n}} /$ $Q_{\mathrm{n}} \approx \mathrm{d} R_{\mathrm{n}} / R_{\mathrm{n}}$ in a first order analysis. The collection of time series as well as the experimental setup used to test the simplified carbon-water model (Eqs. (1) and (5)) and evaluate how GCM precipitation projections can be used to predict $\mathrm{d} D$ and $\mathrm{d} Q_{\mathrm{n}}$ are discussed next.

\section{Experiment}

The experimental site is a grass covered flat catchment located in North Cork, Ireland $(51.90 \mathrm{~N}, 8.47$ $\mathrm{W}, 195 \mathrm{~m}$ above mean sea level). The grassland type is mainly $\mathrm{C} 3$ pasture and meadow, varying in height between 5 and $50 \mathrm{~cm}$, and the soil profile consists of a top layer of humus (10-15 cm thick) and a subsoil layer of sandy loam ( $45 \mathrm{~cm}$ thick). The surface roughness for momentum of this site is around $0.03 \mathrm{~m}$. An eddycovariance system which consists of a sonic anemometer (RM Young 8100) and an open-path $\mathrm{CO}_{2} / \mathrm{H}_{2} \mathrm{O}$ gas analyzer (Licor 7500) was used to measure $\mathrm{CO}_{2}$ and water vapor fluxes at $10 \mathrm{~m}$ above the soil surface. The sampling frequency and duration were $10 \mathrm{~Hz}$ and $30 \mathrm{~min}$, respectively. The $R_{\mathrm{n}}$ and $G_{\mathrm{s}}$ were measured at $10 \mathrm{~m}$ above the surface and $5 \mathrm{~cm}$ below the surface, respectively. Mean meteorological parameters, including $P$, measured at $0.5 \mathrm{~m}$ above the soil surface, and $T_{\mathrm{a}}$ and $D$ were measured at $3 \mathrm{~m}$ above the soil surface. Soil temperature $\left(T_{\mathrm{s}}\right)$ and soil moisture were also measured at both $2.5 \mathrm{~cm}$ and $5.0 \mathrm{~cm}$ below the surface. With the exception of the eddy-covariance system, all measurements were sampled at $1 \mathrm{~min}$ and averaged (or summed) every $30 \mathrm{~min}$. Data collection commenced on July 1, 2001 and is continuously running as part of a long-term CELTICFLUX monitoring initiative. The data set used here is the 2002 subset.

\section{Results and discussion}

In this section, we assess the simplified water-carbon model performance and then proceed to quantify the effects of climate shifts on $A$.

\subsection{Evaluating the simplified water-carbon model}

The primary assumption in (5) is that the transpiration rate is well approximated by the Penman-Monteith formula. We tested this formula in Fig. 1, which compares modeled latent heat flux $\left(\mathrm{LE}_{\mathrm{M}}\right)$ with eddycovariance measured $\left(\mathrm{LE}_{\mathrm{EC}}\right)$ water vapor flux. The coefficient of determination $\left(R^{2}\right)$ and the root-mean square error (RMSE) for Fig. 1 are 0.81 and $25\left(\mathrm{~W} \mathrm{~m}^{-2}\right)$, respectively, and suggest that the agreement between measured and modeled LE is sufficiently accurate for canopy conductance and photosynthesis calculations.

Eddy-covariance systems can measure net ecosystem carbon exchange (NEE) but not $A$. Notice that $\mathrm{NEE}=-A+R_{\mathrm{E}} ; R_{\mathrm{E}}=$ ecosystem respiration. Hence,

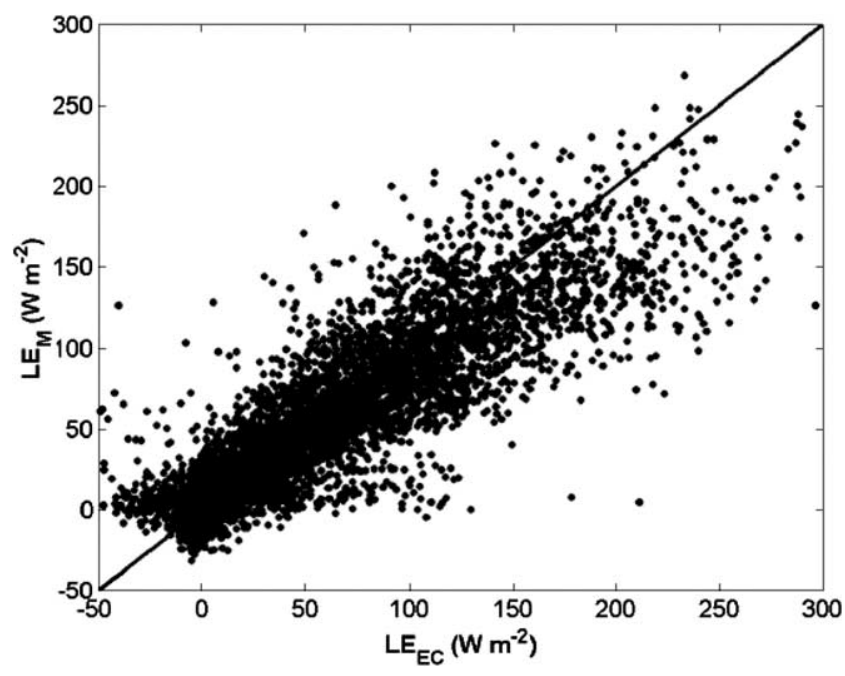

Fig. 1. Comparison between modeled latent heat flux $\left(\mathrm{LE}_{\mathrm{M}}\right)$ by the Penman-Monteith equation and eddy-covariance measured ( $\left.\mathrm{LE}_{\mathrm{EC}}\right)$ water vapor flux. The 1:1 line is also shown. 
Eq. (5) cannot be explicitly tested with measured NEE. An indirect test of modeled $A$ by (5) can be conducted if measured nighttime $\mathrm{CO}_{2}$ fluxes are used to calibrate a respiration model that is then used to compute daytime ecosystem respiration $\left(R_{\mathrm{E}}\right)$. By combining modeled $A$ with modeled $R_{\mathrm{E}}$, a comparison between measured and modeled NEE can be conducted. This comparison serves as an indirect test for modeled $A$ (i.e., Eq. (5)) because all the errors in the $R_{\mathrm{E}}$ model will express themselves in the NEE model. One can also subtract modeled $R_{\mathrm{E}}$ from measured NEE to get a "measured" $A$ and use this value to test the model performance by (5). Both methods are analogous.

To obtain the respiration model, measured night-time NEE were regressed upon $T_{\mathrm{s}}$ using a standard $Q_{10}$ model

$R_{\mathrm{E}}=R_{\mathrm{E}, 10}\left(Q_{10}\right)^{\frac{T_{\mathrm{s}}-10}{10}}$,

where $Q_{10}$ and $R_{\mathrm{E}, 10}\left(\mu \mathrm{mol} \mathrm{m}{ }^{-2} \mathrm{~s}^{-1}\right)$ are respiration temperature sensitivity and base respiration at $10^{\circ} \mathrm{C}$, respectively. Fig. 2 shows the measured dependence of $R_{\mathrm{E}}$ on $T_{\mathrm{s}}$ along with the regression fit to (7). The scatter in Fig. 2 is large $\left(R^{2}=0.12, \quad\right.$ RMSE $=$ $0.72 \mu \mathrm{mol} \mathrm{m}^{-2} \mathrm{~s}^{-1}$ ) but typical of such ecosystem $R_{\mathrm{E}}$ models [17]. We also noticed that the residuals (i.e., the difference between measured and modeled $R_{\mathrm{E}}$ ) do not depend on soil moisture. Using measured night-time NEE for a friction velocity $\left(u_{*}\right)>0.2 \mathrm{~m} \mathrm{~s}^{-1}$, we compute a $Q_{10}=2.02$ and a $R_{\mathrm{E}, 10}=3.57$ which are also consistent with reported values for temperate grassland ecosystems experiencing periodic harvesting [17]. Here the criterion of nocturnal $u_{*}>0.2$ is to ensure that the nocturnal flow is fully turbulent (i.e., no canopy waves or other transient non-turbulent phenomena are present) and that the $\mathrm{CO}_{2}$ storage flux (i.e., $\mathrm{CO}_{2}$ stored between the sur-

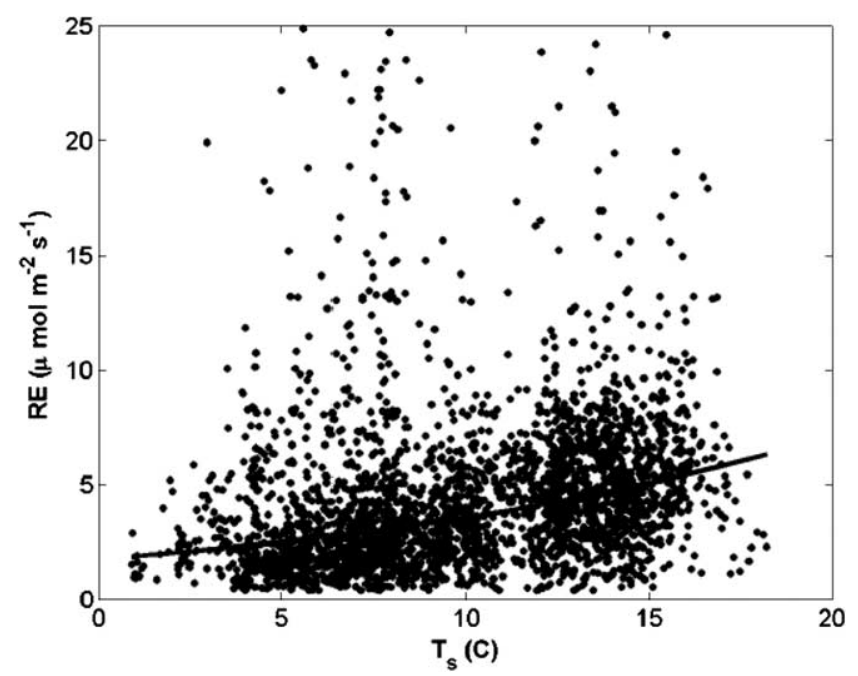

Fig. 2. Variation of measured nighttime ecosystem respiration $\left(R_{\mathrm{E}}\right)$ with soil temperature $T_{\mathrm{s}}$ for friction velocity $(u *)>0.2 \mathrm{~m} \mathrm{~s}^{-1}$. The solid line represents Eq. (7). face and the eddy-covariance sensor height) is minimal so that the eddy-covariance technique represents $R_{\mathrm{E}}$ (see [5] for detailed discussion). Furthermore, this criterion ensures that the footprint of the nighttime respiration (and hence the derived $Q_{10}$ and $R_{\mathrm{E}, 10}$ ) is not much larger than its near-neutral daytime value (i.e., the source area contributing to nighttime measurements is comparable to the source area contributing to the daytime NEE measurements for spatial scalability of the nighttime derived respiration function to daytime). Modeled NEE is then given by $-A+R_{\mathrm{E}}$, where $A$ is computed from (5) with $C_{\mathrm{a}}=355 \mathrm{ppm}$ assuming a constant $C_{\mathrm{i}} / C_{\mathrm{a}}=0.84$ (for $C_{3}$ type grasses), and $R_{\mathrm{E}}$ is computed from (7). The comparison between predicted and measured NEE is shown in Fig. 3. Given the scatter in $R_{\mathrm{E}}$, the agreement between measured and modeled NEE is reasonable $\left(R^{2}=0.42, \mathrm{RMSE}=6.13 \mu \mathrm{mol} \mathrm{m}^{-2} \mathrm{~s}^{-1}\right)$.

\subsection{Relating projected shifts in climatic forcing to photosynthesis}

To calculate the projected shift in photosynthesis using $(6 \mathrm{~b}), \mathrm{d} C_{\mathrm{a}}, \mathrm{d} Q_{\mathrm{n}}, \mathrm{d} D, \mathrm{~d}\left(C_{\mathrm{i}} / C_{\mathrm{a}}\right)$, and $\mathrm{d} r_{\mathrm{st}}$ are all needed. As earlier stated, our climate projections for $\mathrm{d} C_{\mathrm{a}}$ (and meteorological variables that permit us to determine $\mathrm{d} Q_{\mathrm{n}}, \mathrm{d} D$ ) are based on the Hadley Center GCM output of the IS92a scenario for Ireland in which $C_{\mathrm{a}}$ doubles over the course of the 21 st century. The scenario is based on a 'business as usual emission rate assuming a mid-range economic growth but no measures to reduce greenhouse gas emissions are taken. The GCM output used in this study is based on the HadCM3, which is a new generation of high-resolution coupled atmosphere-ocean general circulation model described by Gordon et al. [9] and Pope et al. [18].

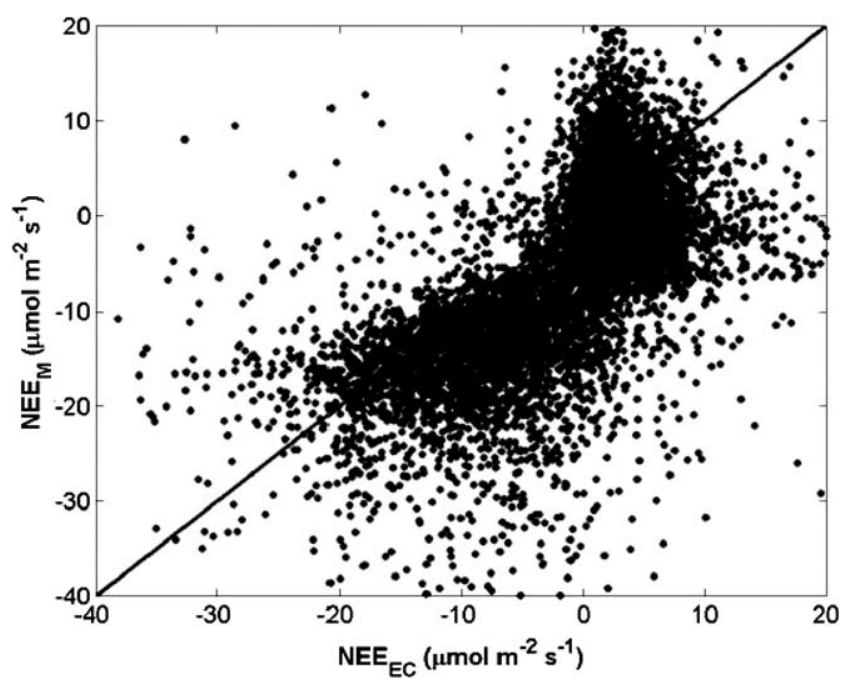

Fig. 3. Comparison between predicted $\left(\mathrm{NEE}_{\mathrm{M}}\right)$ and measured $\left(\mathrm{NEE}_{\mathrm{EC}}\right)$ net ecosystem exchange. The 1:1 line is also shown. 
Under the IS92a scenario, the GCM uses current $C_{\mathrm{a}}=350 \mathrm{ppm}$ and a future $C_{\mathrm{a}}=700 \mathrm{ppm}$; hence, $\mathrm{d} C_{\mathrm{a}}=$ $700-350=350 \mathrm{ppm}\left(\right.$ and $\left.\mathrm{d} C_{\mathrm{a}} / C_{\mathrm{a}}=350 / 350=1\right)$. When evaluating how climatic shifts in $\mathrm{d} Q_{\mathrm{n}}, \mathrm{d} D$ alone effects $A$ in Eq. (6b), we assume static physiological properties (i.e., both $\mathrm{d}\left(C_{\mathrm{i}} / C_{\mathrm{a}}\right)$ and $\mathrm{d} r_{\text {st }}$ are zero). The HadCM3 does not provide output data for $\mathrm{d} Q_{\mathrm{n}}$ and $\mathrm{d} D$, but provides seasonal variations in $\mathrm{d} P$. Hence, both $\mathrm{d} Q_{\mathrm{n}}$ and $\mathrm{d} D$ must be related to seasonal shifts in $P$ (i.e., $\mathrm{d} P$ ) using existing meteorological measurements at the site. Both $\mathrm{d} Q_{\mathrm{n}}$ and $\mathrm{d} D$ can be related to $\mathrm{d} P$ using

$\mathrm{d} Q_{\mathrm{n}} \approx \frac{\partial Q_{\mathrm{n}}}{\partial P} \mathrm{~d} P ; \quad \mathrm{d} D \approx \frac{\partial D}{\partial P} \mathrm{~d} P$

where $\partial Q_{\mathrm{n}} / \partial P$ and $\partial D / \partial P$ are evaluated from time series of $Q_{\mathrm{n}}, P$, and $D$ collected at the site as follows: (1) first ensemble-average $Q_{\mathrm{n}}$ and $D$ (denoted by angle brackets $\langle\cdot\rangle$ ) during daylight hours for different daily precipitation intensity bins, (2) apply a power-law relation to derive the expected decrease in $\left\langle Q_{\mathrm{n}}\right\rangle$ and $\langle D\rangle$ with increasing $\langle P\rangle$ (mm day ${ }^{-1}$ ), and (3) compute $\left\langle\partial Q_{\mathrm{n}} / \partial P\right\rangle$ and $\langle\partial D / \partial P\rangle$ from the derived relationship in step 2. Kumagai et al. [13] successfully used such an approach to assess how precipitation shifts affect water cycling in a Bornean tropical rain forest under current and projected precipitation scenarios. Fig. 4 shows these measured relationships along with the best-fit power-law curves. We found that $\left\langle Q_{\mathrm{n}}\right\rangle=195\langle P\rangle^{-0.65}$ and $\langle D\rangle=0.3\langle P\rangle^{-0.31}$ represent the ensemble data at the site reasonably well (Fig. 4).

Using these relations and noting that the annual average precipitation intensity is about $4.89 \mathrm{~mm} \mathrm{day}^{-1}$ at the site, we estimate: $\partial Q_{\mathrm{n}} / \partial P=-9.24 \mathrm{~W} \mathrm{~m}^{-2}(\mathrm{~mm}$ $\left.\mathrm{day}^{-1}\right)^{-1} ; \partial D / \partial P=-0.012 \mathrm{kPa}\left(\mathrm{mm} \mathrm{day}^{-1}\right)^{-1}$. Again, the negative sign in the partial derivatives is not a surprise, as increases in precipitation ought to result in
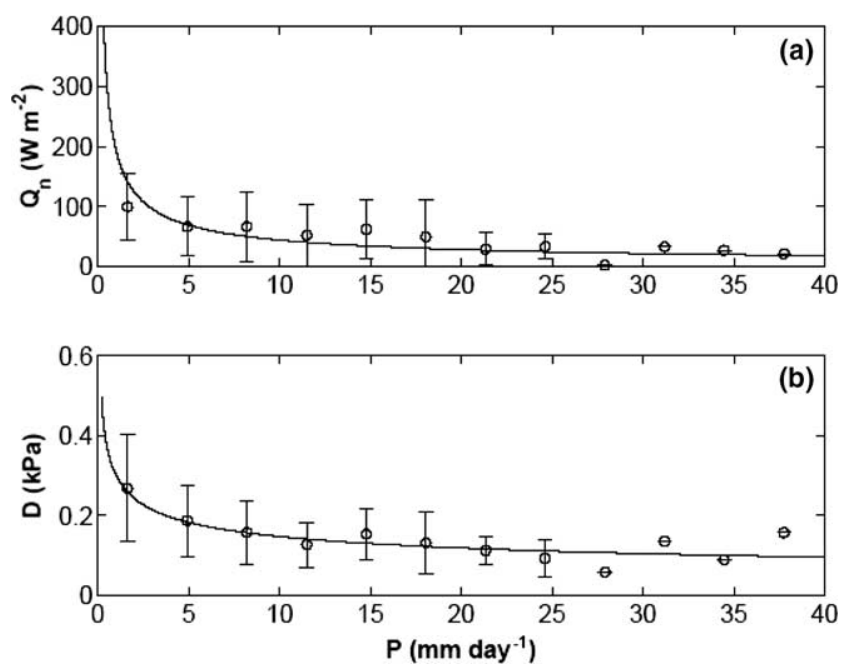

Fig. 4. (a) Mean (open circles) and standard deviation (vertical bar) of measured daytime radiation $\left(Q_{\mathrm{n}}\right)$ versus daily precipitation $(P)$. The solid line is regression curve. (b) Same as (a) but for vapor pressure deficit $(D)$. simultaneous decreases in net radiation and vapor pressure deficit. While a decrease in vapor pressure deficit leads to an increase in $A$, the decrease in $Q_{\mathrm{n}}$ leads to a decrease in $A$ as evidenced from Eq. (6b) leading to a cancellation effect.

For December, January, and February (DJF), the mean $Q_{\mathrm{n}}, D, \Delta$, and $r_{\mathrm{av}}$ are $16.0\left(\mathrm{~W} \mathrm{~m}^{-2}\right), 0.14(\mathrm{kPa})$, $0.067\left(\mathrm{kPa} \mathrm{K}^{-1}\right)$, and $28.6\left(\mathrm{~s} \mathrm{~m}^{-1}\right)$ respectively, and the HadCM3 predicts a $P$ increase of $0.55 \mathrm{~mm} \mathrm{day}^{-1}$ for Ireland. Hence, with these estimates and with $\mathrm{d} C_{\mathrm{a}} / C_{\mathrm{a}}=1$ (i.e., a doubling of $\mathrm{CO}_{2}$ concentration) and no physiological shift (i.e., $\mathrm{V}+\mathrm{VI}=0$ ), we estimate $\mathrm{d} A / A=0.96$. For March, April, and May (MAM) and for September, October, and November (SON), the GCM reported $\mathrm{d} P=0$ resulting in $\mathrm{d} A / A=1$. For June, July, and August (JJA), the mean $Q_{\mathrm{n}}, D, \Delta$, and $r_{\mathrm{av}}$ are $121.0\left(\mathrm{~W} \mathrm{~m}^{-2}\right), 0.32$ $(\mathrm{kPa}), 0.1\left(\mathrm{kPa} \mathrm{K}^{-1}\right)$, and $28.1\left(\mathrm{~s} \mathrm{~m}^{-1}\right)$ respectively, and the HadCM3 predicts a decrease in $P$ of $0.66 \mathrm{~mm}_{\text {day }}{ }^{-1}$, which leads to $\mathrm{d} A / A=1.01$. When integrating these four seasonal outcomes over the entire year, we found $\mathrm{d} A$ / $A=0.99$. This small departure from unity (i.e., $\mathrm{d} C_{\mathrm{a}} / C_{\mathrm{a}}$ ) is primarily due to the interplay between shifts in precipitation and the asymmetric expected shifts in $D$ and $Q_{\mathrm{n}}$ for DJF and JJA. Recall that, from (6b), a positive shift in $\mathrm{d} D$ results in a decrease in $\mathrm{d} A$, but a positive change in $\mathrm{d} Q_{\mathrm{n}}$ results in an increase in $\mathrm{d} A$. Hence, some influence of $\mathrm{d} D$ on $\mathrm{d} A$ is canceled, as expected, by $\mathrm{d} Q_{\mathrm{n}}$.

\subsection{Discussion}

To address our primary objective, we compare our computed $\mathrm{d} A / A=0.99$ derived from only climate shifts with other experimental studies that only evaluated physiological adjustments (i.e., assuming III $=0$ and $\mathrm{IV}=0$ ) to elevated $\mathrm{CO}_{2}$. The two grassland ecosystem experiments $[8,11]$ primarily considered in this study were conducted on markedly different climate and soils (Texas, USA and Dublin, Ireland). Both experiments indicate that incident radiation and microclimate within the $\mathrm{CO}_{2}$ enriched grass plots were maintained identical to the control (or ambient) (i.e., III $=0$ and IV $=0$ ). For the Gill et al. [8] experiment in Texas, USA, we calculated $\mathrm{d} A / A$ and $\mathrm{d} C_{\mathrm{a}} / C_{\mathrm{a}}$ from their data reported in Fig. 1 directly. Their experimental data showed that $\mathrm{d} A / A=0.55$ while $\mathrm{d} C_{\mathrm{a}} / C_{\mathrm{a}}=1$. From (6b), we can estimate the physiological adjustments (i.e., V + VI) by

Physiological adjustments $(\mathrm{V}+\mathrm{VI})$

$$
=\mathrm{d} C_{\mathrm{a}} / C_{\mathrm{a}}-\mathrm{d} A / A-(\mathrm{III}-\mathrm{IV}) .
$$

Hence, the shifts by physiological properties for the experiment are $0.45(1-0.55-0+0=0.45)$.

For the Jongen and Jones [11] experiment in Dublin, Ireland, we assumed that (1) their reported net primary productivity (NPP) linearly relates to the gross primary productivity (GPP), and (2) GPP $\approx A$; thereby permit- 
Table 1

The relative importance of ecophysiological adjustments and climate forcing on $\mathrm{d} A / A$ for grasslands while $\mathrm{d} C_{\mathrm{a}} / C_{\mathrm{a}}=1$. (Recall, from $(6 \mathrm{~b}), \frac{\mathrm{d} A}{A}=$ $\left.\frac{\mathrm{d} C_{\mathrm{a}}}{C_{\mathrm{a}}}-\left(\frac{\Delta Q_{\mathrm{n}} \mathrm{d} D}{\left(\Delta Q_{\mathrm{n}}+\rho c_{p} D / r_{\mathrm{av}}\right) D}-\frac{\Delta \mathrm{d} Q_{\mathrm{n}}}{\Delta Q_{\mathrm{n}}+\rho c_{p} D / r_{\mathrm{av}}}\right)-\left(\frac{\left(\gamma / r_{\mathrm{av}}\right) \mathrm{d} r_{\mathrm{st}}}{\Delta+\gamma\left(1+r_{\mathrm{st}} / r_{\mathrm{av}}\right)}+\frac{\mathrm{d}\left(C_{\mathrm{i}} / C_{\mathrm{a}}\right)}{1-\left(C_{\mathrm{i}} / C_{\mathrm{a}}\right)}\right) \mathrm{I}=\mathrm{II}-(\mathrm{III}-\mathrm{IV})-(\mathrm{V}+\mathrm{VI})\right)$

\begin{tabular}{lll}
\hline Study & $\mathrm{d} A / A$ & Remarks \\
\hline Reference state & 1.0 & $\begin{array}{l}\text { No climate or physiological adjustment occurs } \\
\left.\text { (i.e., III }=\mathrm{IV}=\mathrm{V}=\mathrm{VI}=0 \text {; hence, } \mathrm{d} A / A=\mathrm{d} C_{\mathrm{a}} / C_{\mathrm{a}}-0=1-0=1\right)\end{array}$ \\
Gill et al. [8] & No climate shift occurs in this experiment $($ i.e., III $=\mathrm{IV}=0)$ \\
Jongen and Jones [11] & 0.55 & No climate shift occurs in this experiment $($ i.e., III $=\mathrm{IV}=0)$ \\
Current model results & 0.58 & No physiological adjustment occurs (i.e., V V $=\mathrm{VI}=0)$ \\
\hline
\end{tabular}

ting us to calculate $\mathrm{d} A / A$ from their measured $\mathrm{dNPP} /$ NPP for the reported $\mathrm{d} C_{\mathrm{a}} / C_{\mathrm{a}}$. Their measurements showed that $\mathrm{d} A / A=0.58$ while $\mathrm{d} C_{\mathrm{a}} / C_{\mathrm{a}}=1$. Hence, the physiological adjustments for this experiment are 0.42 $(1-0.58-0+0=0.42)$. Surprisingly, these two experiments suggest consistent physiological adjustments $(\approx 0.45)$ with elevated $\mathrm{CO}_{2}$ despite climate and soil differences across these two experiments. The $\mathrm{d} A / A$ values from these two experiments and our study are summarized in Table 1.

Our study shows that $\mathrm{d} A / A=0.99$ while $\mathrm{d} C_{\mathrm{a}} / C_{\mathrm{a}}=1$ and without physiological adjustments (i.e., $\mathrm{V}=0$ and $\mathrm{VI}=0$ ). Again, from $(6 \mathrm{~b})$, the climate shifts can be calculated as

Climate shifts $(\mathrm{III}-\mathrm{IV})=\mathrm{d} C_{\mathrm{a}} / C_{\mathrm{a}}-\mathrm{d} A / A-(\mathrm{V}+\mathrm{VI})$.

Hence, the adjustments by climatic factors for our study are $0.01(1-0.99-0-0=0.01)$. It is clear that, for these two studies, the physiological adjustment $(\mathrm{V}+\mathrm{VI} \approx 0.45)$ is about 45 times more important than the expected shifts in climate-forcing terms (III IV $\approx 0.01$ ) derived from the IS92a projected climate scenario for Ireland. Again, an important reason why the shifts in climate forcing on $A$ is small relative to the physiological adjustment is because an increase in $P$ leads to concomitant decreases in $\mathrm{d} D$ and $\mathrm{d} Q_{\mathrm{n}}$, and decreases in $\mathrm{d} D$ and $\mathrm{d} Q_{\mathrm{n}}$ have opposite (and almost canceling) effects on $\mathrm{d} A$. Considering only cloud cover or vapor pressure deficit in isolation would have yielded an erroneous conclusion about the relative importance of climatic forcing shifts on $\mathrm{d} A$.

\section{Implications}

Based on our model calculations in conjunction with reported elevated $\mathrm{CO}_{2}$ experiments for grasslands, two broad implications emerge from our analysis:

(1) A recent study by Cox et al. [6] demonstrated that climate models with "dynamic" vegetation predict a drastically different climate and terrestrial carbon sink when compared with their "static" land cover counterparts. For these models, the need to account for a realistic reduction in $g_{\mathrm{CO}_{2}}\left(1-C_{\mathrm{i}} / C_{\mathrm{a}}\right.$ ) (or down-regulation) with elevated atmospheric $\mathrm{CO}_{2}$ is equally critical to resolving correct climate forcing terms for future climate scenarios.

(2) The Kyoto Protocol allows countries to obtain carbon credits (or get carbon debits) for forest activities to help meet commitments in reducing greenhouse gas emissions. Such allowance is now promoting aggressive afforestation policy in several European countries, most notably in Ireland, in which afforestation aims at increasing forested lands from $9 \%$ (in 2000) to 17\% (in 2030) as described by Anon [1]. Given that a large portion of land cover $(\sim 45 \%)$ in Ireland will remain predominantly pasture and farmed grasslands, a logical first step is to quantify the magnitude of the carbon sink in such grasslands but for a future climate scenario. By (6b), for a $100 \%$ increase in elevated $\mathrm{CO}_{2}$, the increase in photosynthesis after reductions by physiological adjustment $(\sim 45 \%)$ and climate shifts $(\sim 1 \%)$ is still $54 \%$. This study also points out that future research efforts should focus on the magnitude of the physiological adjustments of grassland ecosystems under elevated atmospheric $\mathrm{CO}_{2}$ as it can be much larger than expected climate forcing shifts.

\section{Acknowledgments}

We would like to thank the two anonymous reviewers for their helpful comments. Hsieh acknowledges support from the National Science Council, Taiwan; Kiely acknowledges support from the ERTDI program managed by the Irish EPA and funded by the Irish Government under the National Development Plan, 2000-2006 (CELTICFLUX, 2001-CC-C2-M1), and Katul acknowledges support from the Department of Energy's terrestrial carbon processes (TCP) program, the National Institute for Global Environmental Change (NIGEC) Southeast Regional Center at University of Alabama, Tuscaloosa, and the National Science Foundation (NSF-EAR).

\section{References}

[1] Anon. Irish National Forest Standard. Forest Service, Dept. of the Marine and Nat. Res, Dublin, Ireland, 2000. 
[2] Betts RA, Cox PM, Lee SE, Woodward FI. Contrasting physiological and structural vegetation feedbacks in climate change simulations. Nature 1997;387:796-9.

[3] Brutsaert W. Evaporation into the atmosphere. Netherland: Kluwer Academic Publishers; 1984. p. 70.

[4] Campell GS, Norman JM. An introduction to environmental biophysics. New York: Springer-Verlag; 1998. p. 238.

[5] Cava D, Giostra U, Siqueira M, Katul G. Organised motion and radiative perturbations in the nocturnal canopy sublayer above an even-aged pine forest. Bound-Lay Meteorol 2004;112:12957.

[6] Cox PM, Betts RA, Jones CD, Spall SA, Totterdell IJ. Acceleration of global warming due to carbon-cycle feedbacks in a coupled climate model. Nature 2000;408:184-7.

[7] Ehleringer JR, Cerling TE. Atmospheric $\mathrm{CO}_{2}$ and the ratio of intercellular to ambient $\mathrm{CO}_{2}$ concentrations in plants. Tree Physiol 1995;15:105-11.

[8] Gill R, Polley HW, Johnson HB, Andreson LJ, Maherali H, Jackson RB. Nonlinear grassland responses to past and future atmospheric $\mathrm{CO}_{2}$. Nature 2002;417:279-82.

[9] Gordon C, Cooper C, Senior CA, Banks HT, Gregory JM, Johns TC, et al. Simulation of SST, sea ice extents and ocean heat transports in a version of the Hadley Center coupled model without flux adjustments. Climate Dyn 2000;16:147-68.

[10] Jackson RB, Banner JL, Jobbagy EG, Pockman WT, Wall DH. Ecosystem carbon loss with woody plant invasion of grasslands. Nature 2002;418:623-6.

[11] Jongen M, Jones MB. Effects of elevated carbon dioxide on plant biomass production and competition in a simulated neutral grassland community. Ann Botany 1998;82:111-23.
[12] Katul GG, Ellsworth D, Lai CT. Modeling assimilation and intercellular $\mathrm{CO}_{2}$ from measured conductance: $\mathrm{A}$ synthesis of approaches. Plant Cell Environ 2000;23:1313-28.

[13] Kumagai T, Katul GG, Saitoh TM, Sato Y, Manfroi OJ, Morooka T, et al. Water cycling in a Bornean tropical rain forest under current and projected precipitation scenarios. Water Resour Res 2004:40:W01104.

[14] Liu S, Teskey RO. Responses of foliar gas exchange to long-term elevated $\mathrm{CO}_{2}$ concentration in mature loblolly pine trees. Tree Physiol 1995;15:351-9.

[15] Luo Y, Medlyn B, Hui D, Ellsworth D, Reynolds J, Katul GG. Gross primary productivity in Duke Forest: Modeling synthesis of $\mathrm{CO}_{2}$ experiment and eddy-flux data. Ecol Appl 2001;11:239-52.

[16] Medlyn BE, Badeck F-W, De Pury DGG, Barton CVM, Broadmeadow M, Ceulemans R, et al. Effects of elevated atmospheric $\mathrm{CO}_{2}$ on photosynthesis in European forest species: A meta-analysis of model parameters. Plant Cell Environ 1999;22:1475-95

[17] Novick KA, Stoy PC, Katul GG, Ellsworth DS, Siquira MBS, Juang $\mathbf{J}$, et al. Carbon dioxide and water vapor exchange in a warm temperature grassland. Oecologia 2004;138:259-74.

[18] Pope VD, Gallani ML, Rowntree PR, Stratton RA. The impact of new physical parametrizations in the Hadley Centre climate model-HadAM3. Climate Dyn 2000;16:123-46.

[19] Sellers PJ, Bounoua L, Collatz GJ, Randall DA, Dazlich DA, Los $\mathrm{SO}$, et al. Comparison of radiative and physiological effects of doubled atmospheric $\mathrm{CO}_{2}$ on climate. Science 1996;271:1402-6.

[20] Shaw MR, Zavaleta ES, Chiariello NR, Cleland EE, Mooney HA, Field CB. Grassland responses to global environmental changes suppressed by elevated $\mathrm{CO}_{2}$. Science 2002;298:1987-90. 